\title{
O052. Migraine without aura and osteopathic medicine, a non-pharmacological approach to pain and quality of life: open pilot study
}

\author{
Vito Adragna*, Andrea S Bertino, Mauro Carano, Alessandro Soru, Giovanna Taranto, Riccardo Desideri \\ From Abstracts from the 1st Joint ANIRCEF-SISC Congress \\ Rome, Italy. 29-31 October 2015
}

\section{Background}

Migraine without aura is the most known and widespread primary headache, more than one person out of 10 suffers from this form. The management of the migraine patient is complex and can not be separated from a pharmacological approach, considering that alternative and complementary therapies are increasingly present in patient management $[1,2]$. This study aimed to verify the efficacy of osteopathic manipulative treatment (OMT) in patients with migraine without aura.

\section{Methods}

Eight subjects, three males and five females with migraine without aura (IHS: 1.1-ICD10:G43.0), selected at a private medical office, were included in a single treatment group. Four treatments were carried out in 8 weeks. Outcome measures were frequency of attacks, drug taking, MIDAS, HIT-6, SF-36 and BAQ (Body Awareness Questionnaire). Outcomes were measured at baseline $\left(t_{0}\right), 1$ month after the last treatment $\left(t_{1}\right)$, and 3 months after the last treatment $\left(t_{2}\right)$, all subjects filled in a headache diary from three months before $t_{0}$ and for the duration of the study and continued drug therapy prescribed.

\section{Results}

In the first session there was a prevalence of $100 \%$ of somatic dysfunctions (SD) in C1-occipital joint and in the other session a prevalence of $37 \%$ in the same joint (Table 1) was detected. Between sessions of OMT a reduction of SD was observed showing a significant reduction of total dysfunction at third $(\mathrm{p}=0.01)$ and fourth $(\mathrm{p}=0.001)$ treatment (Figure 1), the SD Musculoskeletal at fourth

\footnotetext{
* Correspondence: ricerca@csot.it

Research Department, Study Centre for Traditional Osteopathy, Rome, Italy
}

Table 1 Prevalence (\%) of somatic dysfunction per OMT session. Other dysfunctions have reported lower prevalences.

\begin{tabular}{|c|c|c|c|c|c|c|c|c|}
\hline & $\begin{array}{l}\text { Occ/ } \\
\text { C1 }\end{array}$ & $\begin{array}{l}\mathrm{SBS}^{\mathrm{a}} \\
\text { compression }\end{array}$ & $C^{b_{3}}$ & $\mathrm{~T}^{\mathrm{c}} 3$ & $\mathrm{~T}^{\mathrm{c}} 4$ & $\mathrm{~T}^{\mathrm{C}} 5$ & $\mathrm{~T}^{\mathrm{c}} 9$ & Sacrum \\
\hline $\begin{array}{l}\text { OMT } \\
1\end{array}$ & 100 & 87 & & & & & & \\
\hline $\begin{array}{l}\text { OMT } \\
2\end{array}$ & 37 & & 37 & & & 37 & & 37 \\
\hline $\begin{array}{l}\text { OMT } \\
3\end{array}$ & 37 & & 37 & 37 & & & 37 & \\
\hline $\begin{array}{l}\text { OMT } \\
4\end{array}$ & 37 & & 37 & & 37 & & & \\
\hline
\end{tabular}

${ }^{\mathrm{a}}$ Spheno-Basilar Sincondrosy. ${ }^{\mathrm{b}}$ Cervical vertebra. ${ }^{\mathrm{c}}$ Thoracic vertebra.

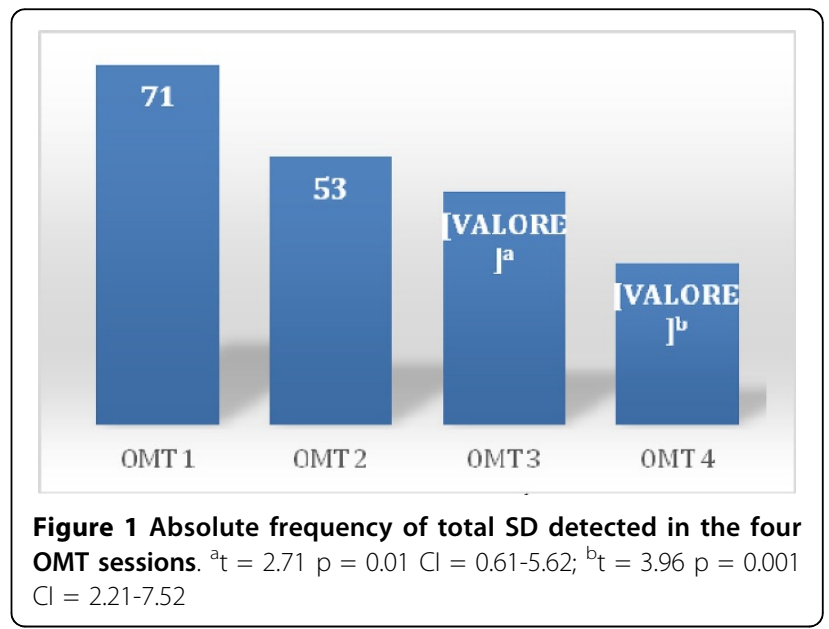

treatment $(\mathrm{p}=0.02)$ (Figure 2) and those of the craniosacral system at the second $(\mathrm{p}=0.04)$, the third $(\mathrm{p}=0.02)$ and fourth $(p=0.001)$ treatment (Figure 3$)$. Significant results were observed on the HIT-6 scale at $t_{2}(p=0.05)$ 

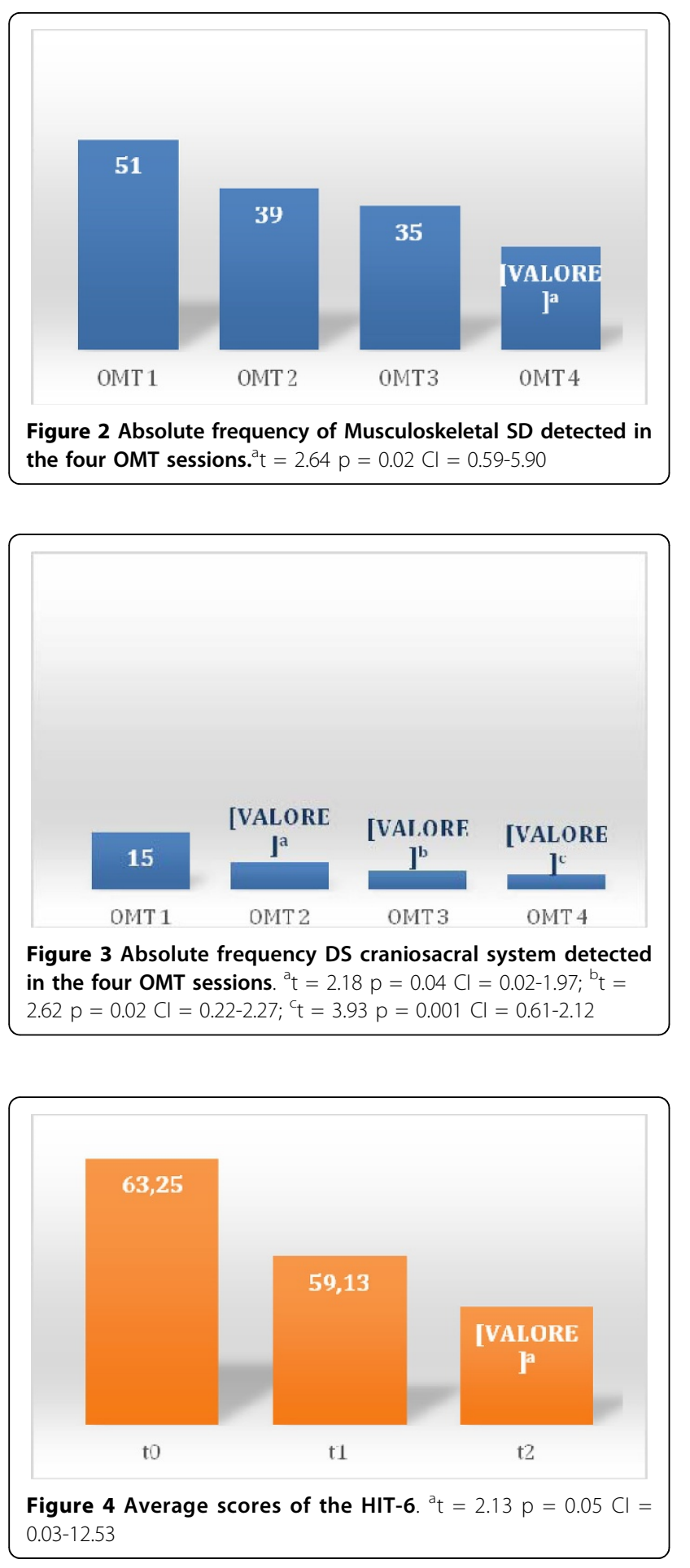

(Figure 4), MIDAS b scale score at $t_{1}(p=0.01)$ and $t_{2}(p=$ $0.03)$ (Figure 5) and SF-36 scale at $t_{1}(p=0.02)$ and $t_{2}(p=$ 0.01 ) (Figure 6). BAQ, the other item of MIDAS and the results of the headache diary, despite the reduction in the scores, did not produce significant results in the days of migraine attacks and medication taking (Figure 7).
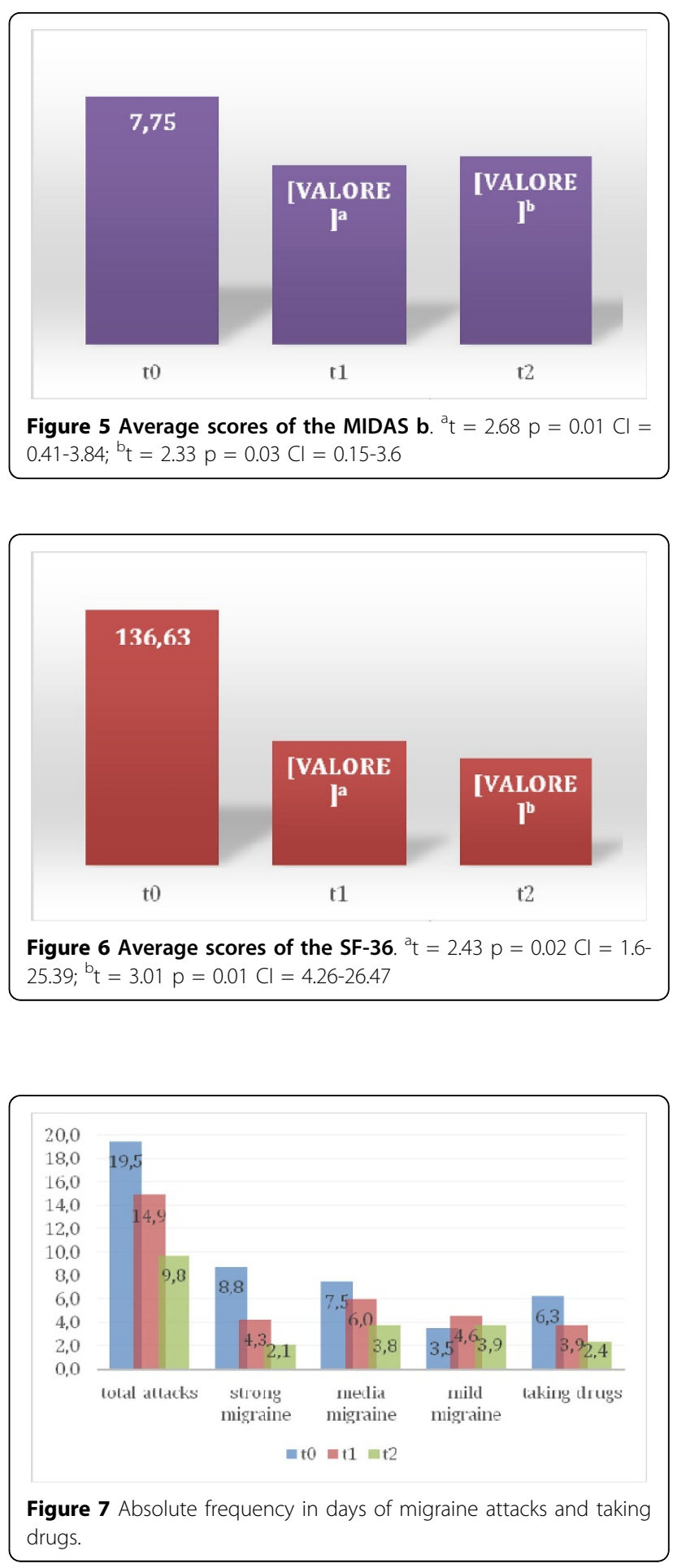

\section{Conclusions}

This study suggests that OMT has a positive effect on pain reduction and quality of life improvement in patients with migraine without aura. Future studies, contemplate including assessment of anxiety and depression, the use of a control group and follow-up in the long term. 
Written informed consent to publish was obtained from the patient(s).

Published: 28 September 2015

\section{References}

1. Chaibi A, Tuchin PJ, Russell MB: Manual therapies for migraine: a systematic review. J Headache Pain 2011, 12(2):127-133.

2. Voigt $K$, Liebnitzky J, Burmeister U, Sihvonen-Riemenschneider $H$, Beck M, Voigt $R$, et al: Efficacy of osteopathic manipulative treatment of female patients with migraine: results of a randomized controlled trial. J Altern Complement Med 2011, 17(3):225-230.

doi:10.1186/1129-2377-16-S1-A180

Cite this article as: Adragna et al.: 0052. Migraine without aura and osteopathic medicine, a non-pharmacological approach to pain and quality of life: open pilot study. The Journal of Headache and Pain 2015 16(Suppl 1):A180.

\section{Submit your manuscript to a SpringerOpen ${ }^{\odot}$ journal and benefit from:}

- Convenient online submission

- Rigorous peer review

- Immediate publication on acceptance

- Open access: articles freely available online

- High visibility within the field

- Retaining the copyright to your article

Submit your next manuscript at $>$ springeropen.com 